\title{
POR QUE ENSINAR QUÍMICA?
}

\author{
Everton Bedin \\ Universidade Federal do Paraná - UFPR, Brasil
}

\begin{abstract}
Resumo
Considerando que existem diferentes objetivos para ensinar e aprender química na Educação Básica, seja para possibilitar ao aluno a formação de uma identidade crítico-científica ou para desenvolver os objetos de conhecimento desta ciência, o propósito/foco deste artigo concentra-se na teia de apresentar, a partir de um estudo sistemático sobre as razões e os motivos de "Por que ensinar química?", apresentados por um grupo de professores sobre tal problematização. Para tanto, este estudo de cunho quali-quantitativo no viés de uma análise estatística-interpretativa, desenha-se a partir de 7 assertivas dispostas em um formulário online com base na escala Likert, disponibilizado via link para um grupo de 92 professores de química. As assertivas foram analisadas de forma mista, considerando a emersão dos dados qualitativos com referência interpretativa por meio dos dados quantitativos via análise estatística no Programa Statistical Package for the Social Sciences. Ao término, além de se perceber que a maioria do grupo de professores se caracteriza como sendo do gênero feminino, tendo idade igual ou superior a 45 anos e possuindo doutorado, inferiu-se uma sequência lógica de razões para desenvolver o ensino de química na Educação Básica. Ademais, percebeu-se que o ensino de química se encaminha para um processo significativo de aprendizagem, no qual o professor assume uma identidade pautada na concepção de que o mesmo deve ser desenvolvido com ênfase na formação crítico-científica de pessoas.
\end{abstract}

Palavras-chave: Ensino de química; Ensino-aprendizagem; Formação discente.

\begin{abstract}
Considering that there are different objectives to teach and learn chemistry in Basic Education, either to enable the student to form a critical-scientific identity or to develop the objects of knowledge of this science, the purpose/focus of this article is concentrated on the web of presenting, based on a systematic study on the reasons and motives of "Why teach chemistry?", presented by a group of teachers about such problematization. For this purpose, this quali-quantitative study in the bias of a statistical-interpretative analysis is drawn from 7 statements arranged in an online form based on the Likert scale, made available via link to a group of 92 chemistry teachers. The assertions were analyzed in a mixed way, considering the emergence of qualitative data with interpretative reference through quantitative data via statistical analysis in the Statistical Package for the Social Sciences Program. In the end, in addition to realizing that the majority of the group of teachers is characterized as being female, aged 45 or over and have a doctorate, a logical sequence of reasons for developing chemistry teaching in Education was inferred Basic. Also, it was noticed that the teaching of chemistry leads to a significant learning process, in which the teacher assumes an identity based on the conception that it should be developed with an emphasis on the critical-scientific formation of people.
\end{abstract}

Keywords: Chemistry teaching; Teaching-learning; Student training.

ISSN 1645-1384 (online) www.curriculosemfronteiras.org 


\section{Concepções iniciais}

Uma das principais linhas de investigação em Educação Química, e que tem ganhado espaço significativo nos últimos tempos, concentra-se basicamente nas investigações sobre a interação que envolve a tríade aluno-professor-saber químico. As pesquisas realizadas nesta linha de investigação, embora possuam como premissa analisar e discutir as interferências dos vieses desta tríade, principalmente em relação à formação de um sujeito crítico e participativo em questões que permeiam a sociedade, muitas vezes, elucidam transformações qualitativas em relação aos processos de ensino e aprendizagem da química. Neste sentido, existem diferentes formas e modos de conceber a qualidade do ensino de química na Educação Básica seja por meio da regularidade e da formalização em que os conteúdos são trabalhados ou pelas metodologias utilizadas pelos professores no desenvolver dos processos de ensinar e aprender, a fim de reduzir o número de evasão e de reprovação dos sujeitos neste componente curricular (BEDIN, 2019).

Ademais, e por dever a situação mais importante que aqui se destaca, nas investigações que buscam a qualificação da formação do sujeito em um viés sociocientífico, tem-se como premissa a abordagem dos objetos do conhecimento da ciência química a partir do contexto do aluno, almejando uma Educação Química a serviço da formação e da identidade sociocultural e sociohistórica do sujeito. Todavia, sabe-se que a qualidade do desenvolvimento dos processos de ensino e aprendizagem é relativa a diferentes características, dentre elas as questões epistemológicas da formação, as questões didáticometodológicas do desenvolvimento da prática pedagógica, e as questões relacionadas a inovação e a transformação do ensino por meio de ações docentes de cunho humanista.

Nesta perspectiva, o objetivo do presente texto concentra-se no intuito de apresentar, a partir de um estudo impreterível e sistemático sobre as razões e os motivos, apresentados por professores, de "Por que ensinar química?". De outra forma, busca-se entender quais são as concepções de um grupo de professores sobre as razões de ensinar química, as quais se relacionam a este ensino em detrimento de suas ações didático-pedagógicas. Este objetivo se justifica na medida em que se compreende que as concepções dos professores em relação ao "Por que ensinar química?" são construídas idiossincraticamente sobre o ideário pedagógico que se fundamenta a partir de pressupostos teóricos e de reflexões sobre as próprias ações pedagógicas. Logo, sonda-se indícios que possibilitem a identificação destes pressupostos individuais e ao mesmo tempo coletivos de professores que ensinam química.

Acredita-se que as percepções que emergem a partir do questionamento "Por que ensinar química?", considerando a formação de sujeitos ativos e críticos ao longo da Educação Básica, são configuradas a partir da prática pedagógica diária dos professores, condicionada sociopoliticamente e ideologicamente, pois tanto os professores quanto à escola cumprem funções que lhes são direcionadas pela sociedade, a qual é constituída por classes sociais com interesses antagônicos. Em especial, segundo De Moraes e Bedin (2017, p. 115), a escola, "é um dos espaços privilegiados de formação e informação, em que a aprendizagem dos conteúdos deveria encontrar-se em sintonia com as questões sociais e culturais do estudante”. Ainda, acredita-se que a prática pedagógica desenvolvida pelo 
"professor de química não deve se limitar a transmitir conteúdos e significados de símbolos e fórmulas, mas favorecer as atividades psico-cognitivas dos estudantes, fazendo com que os mesmos se tornem importantes personagens na assimilação e ressignificação de conceitos" (BEDIN, 2019, p. 102).

Assim, entende-se que o professor que concebe os objetos de conhecimento da ciência química como algo hierárquico, logicamente organizado e construído a-histórico, como se fosse algo pronto e acabado, possivelmente apresentará uma prática pedagógica, bem como concepções em relação aos motivos de por que ensinar esta ciência, extremamente diferente daquele professor que concebe os objetos do conhecimento da ciência química como algo dinâmico e historicamente construído por homens e mulheres, os quais atendem a diferentes interesses e necessidades sociais, uma vez que a ciência química é uma ciência viva. Em corroboração, sabe-se que o professor que acredita que o aluno aprende química por meio da memorização dos conteúdos, todos transmitidos por um docente detentor do conhecimento, e que preconiza por um processo de repetição exaustivamente, também apresenta concepções em relação à questão supracitada de forma diferenciada daquele professor que entende o aluno como pessoa, a qual aprende os conceitos e os conteúdos desta ciência a partir da construção e da interação coletiva por meio de sucessivas reflexões em relação aos materiais e as atividades que perpassam o seu contexto.

Em síntese, Saviani (2011, p. 13) expõe que "o professor técnico é entendido como aquele que é capaz de entrar numa sala de aula e, aplicando regras relativas à conduta e aos conhecimentos a serem transmitidos, seja capaz de se desempenhar a contento diante dos alunos". Diversamente, o autor reflete que "o professor culto é aquele que domina os fundamentos científicos e filosóficos que lhe permitem compreender o desenvolvimento da humanidade e, a partir daí, realiza um trabalho profundo de formação dos alunos a ele confiados" (SAVIANI, 2011, p. 13).

Este pressuposto é importante para a ação pedagógica vinculada ao ato de ensinar química porque a ciência foi articulada ao mundo do estudante por meio de uma concepção em relação a necessidade de este conhece-la em seu mundo, e não moldada na expectativa convencional de que o aluno precisa entrar no mundo da ciência para adotar a visão de um cientista, e, então, perceber o seu mundo a partir dela (AIKENHEAD, 2009).

Ademais, ainda nos achados de Saviani (2011), encontra-se a concepção de que o sujeito não é um ser passivo, mas um ser que reage perante o seu meio natural e cultural, mostrandose capaz de aceitar, rejeitar ou transformar o meio em que se insere. Neste sentido, acreditase que o ensino de química deve ser desenvolvido para que o indivíduo tenha uma formação cidadã socialmente consciente e participativo, sendo este capaz de interagir com o seu contexto, bem como utilizar o conhecimento científico para moldá-lo a sua necessidade, considerando todas as especificidades e as particularidades deste. Assim, acredita-se que o ensino de química na Educação Básica deve servir não apenas para constituir no sujeito uma aprendizagem científica, moldada a partir dos pressupostos da Alfabetização Científica e do Letramento Tecnológico, mas na perspectiva de possibilitar ao aluno condições suficientemente humanas para que possa conhecer e compreender a realidade e a si mesmo. 
Estas ações ultrapassam as concepções de o aluno analisar e observar a sua realidade apoiado nos saberes científicos (saber), pois estas integram ações de refletir e de entender o contexto criteriosamente seja a partir da própria intervenção (saber-fazer) ou da experiência existencial (saber-ser). É com este propósito que a disciplina de química deve ser desenvolvida na Educação Básica, a fim de contribuir de maneira efetiva e significativa para a constituição cidadã do aluno. Afinal, o potencial da contribuição desta ciência na formação do sujeito decorre da sua própria natureza, como uma ciência que trata para além dos elementos naturais e dos fenômenos artificiais. Em síntese, Bedin (2020, p. 237) afirma que "o ensino de química permite introduzir e explorar as informações relacionadas aos fenômenos naturais e artificiais do contexto do aluno, favorecendo a (re)construção e a ampliação de novos saberes".

Assim, a problematização "Por que ensinar química?" deve estar relacionada às ações de aprender para além de como se arquiteta e funciona a natureza e os fenômenos químicos, onde ocorrem, como ocorrem e por que ocorrem na concretude de lugar, mundo e efeito. Isto é, o ensino precisa possibilitar a promoção de um movimento capaz de assegurar ao aluno uma compreensão significativa de como a ciência é produzida e de o porquê ela é valorizada em nossa sociedade (MARTINS et al., 2003). Logo, entende-se que "o ensino de química deve estar entrelaçado e contextualizado ao conhecimento da realidade do educando, favorecendo momentos em que este possa atuar como autor na construção dos próprios saberes" (BEDIN, 2019, p. 103). Portanto, a leitura da ciência química na realidade do sujeito não deve se restringir a descrição das substâncias encontradas na natureza e das suas relações com o ambiente e os seres vivos, mas na busca de entender as suas aplicações e as suas implicações imprescindíveis à vida.

Deste entendimento sobre a química, deriva a sua importância, bem como a sua significação como conteúdo de ensino e de aprendizagem na Educação Básica. Assim, tornase necessário instigar que as ações relacionadas a esta ciência sejam desenvolvidas em um viés contextualizado e dinâmico, uma vez que a compreensão dos fenômenos da natureza de forma microscópica é uma das bases para o efeito significativo do aproveitamento desta ciência em relação ao contexto do aluno. Ademais, a química de forma contextualizada é essencial para que o aluno a perceba interligada "a qualidade de vida e a manutenção consciente do meio ambiente, pois, além de despertar habilidades cognitivas e motoras, a contextualização, quando realizada com eficiência, é capaz de mobilizar competências e saberes nos alunos" (FINGER; BEDIN, 2019, p. 12). Neste enfoque, o ensino de química não pode se circunscrever há uma programação curricular meramente científica e informativa, devendo apresentar-se como um movimento cultural e científico no contexto social e histórico do sujeito, possibilitando-lhe um desenvolvimento intelectual atitudinal, procedimental e conceitual.

Nesta ótica, em relação ao desenvolvimento intelectual atitudinal, ressalva-se que cabe ao ensino de química na Educação Básica possibilitar ao aluno a compreensão de mundo a partir de uma perspectiva crítico-científica, a qual deve estar ao encontro de seus princípios a partir de suas experiências de vida, de espaço e de lugar. Afinal, espera-se que o sujeito consiga compreender o mundo em que habita por meio de diferentes formas e vieses, a fim 
de desenvolver atitudes e valores centrados na ética e na moral; estes aspectos são fundamentais para que o sujeito construa uma identidade crítico-científica com vistas ao seu espaço, moldando-se a partir de ações coletivas e individuais. Nesta linha, a ideia da concepção conceitual advém da necessidade de o aluno aprender a conhecer, principalmente carregado de uma concepção epistemológica e científica dos objetos de conhecimento da ciência química, a qual enriquece o desenvolvimento intelectual de cunho procedimental, propiciando ao sujeito as habilidades necessárias do saber-fazer.

Destarte, diante do exposto, acredita-se ser importante que o ensino de química na Educação Básica seja desenvolvido em um viés relevante à mobilização de competências, ao desenvolvimento de habilidades e a propagação de atitudes referentes a argumentação crítica e o pensamento científico, possibilitando ao aluno a formação de uma identidade relacionada as múltiplas dimensões atreladas a ciência química. Estes pressupostos banalizam as habilidades básicas do amadurecimento do pensamento, cujo desenvolvimento é favorecido pelo movimento intelectual relacionado as ações práticas no ensino de química seja a partir da análise, da observação, da comparação, da interpretação, da síntese ou mesmo da avaliação, pois estas ações constituem um referencial que possibilita ao sujeito a capacidade de atuar e de desenvolver intervenções necessárias a sua realidade.

Além disso, sabe-se que o ensino de química auxilia o sujeito, a partir da concepção sobre o mundo e sobre a tecnologia, a aproveitar os diferentes materiais para qualificar o seu modo de vida, sem prejudicar e nem deteriorar o meio ambiente, pois esta ciência, a partir de seus conhecimentos epistemológicos, filosóficos e científicos, proporciona ao aluno o exercício do raciocínio, capacitando-o a exigir criticamente ações que corroboram com a sua qualidade de vida, bem como de sua comunidade.

\section{Metodologia da Pesquisa}

A pesquisa aqui descrita enquadra-se em um viés quali-quantitativo de cunho estatísticointerpretativo, considerando os dados analisados de forma mista. Ou seja, após a coleta de dados que ocorreu ao longo de duas semanas, fez-se uma interpretação conjunta dos dados e priorizou-se a forma mista, levando em conta os achados na análise quantitativa de cunho estatístico para emergir a análise qualitativa de natureza interpretativa, uma vez que quando o pesquisador "coleta e analisa dados, integra os achados e extrai inferências usando abordagens ou métodos qualitativos e quantitativos em um único estudo ou programa de investigação" (TASHAKKORI; CRESWELL, 2007, p. 4), está realizando uma análise de índole mista. Neste aporte, de acordo com Dal-Farra e Lopes (2013, p. 70), os "métodos mistos combinam os métodos predeterminados das pesquisas quantitativas com métodos emergentes das qualitativas, assim como questões abertas e fechadas"; logo, "o pesquisador baseia a investigação supondo que a coleta de diversos tipos de dados garanta um entendimento melhor do problema pesquisado" (CRESWELL, 2007, p. 35).

Neste desenho, a coleta de dados para a emersão da análise quantitativa de cunho estatístico, a qual foi realizada por meio do Programa SPSS (Statistical Package for the 
Social Sciences), ocorreu no primeiro semestre do ano de 2020 a partir de um formulário online, elaborado na plataforma Google Forms e disponibilizado a um grupo de 92 professores de química por meio de um link via e-mail, WhatsApp e Facebook. Ressalva-se que a plataforma Google Forms foi selecionada para a constituição do formulário online por possibilitar, dentre várias ferramentas, a coleta de dados de forma real e sistematizada, uma vez que, na medida em que os professores respondiam ao formulário, os dados eram armazenados de forma eletrônica e dispostos em planilha para download via Excel.

Em síntese, o formulário online, constituído a partir da escala Likert de 5 pontos, apresentava 7 assertivas relacionadas a questão: "Por que ensinar química?", as quais exigiam dos professores o apontamento em um grau de concordância. Considerando os 5 graus estipulados na escala Likert, ajuíza-se que a análise foi realizada da seguinte forma: i) o somatório dos apontamentos nos escores 1 e 2, considerados os de menor valor, abrangeu o grau de discordância dos professores sobre as assertivas; ii) os apontamentos no escore 3 , intermediário na escala Likert, caracterizaram a incerteza dos sujeitos sobre as assertivas; e, por fim, iii) o somatório dos escores 4 e 5, os maiores valores na escala Likert, reflete o grau de concordância dos professores. Esta sistematização de concordância ou não em relação as assertivas é importante para entender as médias, os graus mínimos e máximos, bem como os desvios-padrões de cada, os quais emergiram a partir da análise estatística via Programa Statistical Package for the Social Sciences.

Ademais, ressalva-se que para entender estatisticamente os apontamentos docentes sobre os graus de concordância para cada uma das assertivas, realizou-se o teste não paramétrico de Kruscal-Wallis ${ }^{1}$, a fim de comparar as implicações das categorias emergentes (Gênero, Faixa Etária, Maior Grau de Formação) em cada assertiva, considerando-se como significativo um $\mathrm{p}<0,05$. De outra forma, quando a significância apresentar um valor menor que 0,05 , assume-se com $95 \%$ de confiança a hipótese alternativa de que, estatisticamente, há efeito da categoria sobre a assertiva. Para tanto, na Tabela 1 apresenta-se as assertivas e os seus respectivos códigos, os quais serão utilizados nos resultados e discussão.

Tabela 1: Códigos e Assertivas disponibilizadas no formulário online em relação ao questionamento "Por que ensinar química?".

\begin{tabular}{cl}
\hline Código & \multicolumn{1}{c}{ Assertiva } \\
\hline A & Para potencializar a formação científica do meu aluno. \\
B & Para possibilitar ao meu aluno a ação de ler o mundo por meio dos óculos da química. \\
C & Para auxiliar o meu aluno a tornar-se um cidadão ético e consciente cientificamente. \\
D & Para apresentar e desenvolver os conceitos e os conteúdos da ciência química. \\
E & Para proporcionar ao meu aluno o desenvolvimento de uma visão crítico-científica sobre o mundo. \\
F & Para propiciar a Alfabetização Científica, a argumentação crítica e o pensamento científico. \\
G & Para o meu aluno mobilizar as competências e desenvolver as habilidades elencadas na Base \\
& Nacional Comum Curricular. \\
\hline
\end{tabular}

Fonte: dados da pesquisa, 2020. 
Ao tocante, trona-se sagaz explicitar que os critérios que nortearam a elaboração das assertivas presentes na Tabela 1, e apresentadas aos professores, derivaram da análise e da interpretação do pesquisador sobre os elementos que compõem os documentos normativos para o ensino de química, tais como as Diretrizes Curriculares Nacionais (DCN) e a Base Nacional Comum Curricular (BNCC). Além disso, afirma-se que essas assertivas são frutos de uma história de vivências, de diálogos e de trocas de experiências e de saberes nos EDEQ (Encontros de Debates sobre o Ensino de Química) e nos ENEQ (Encontro Nacional de Ensino de Química), principalmente com ênfase na qualificação da formação sociocientífica e cidadã do aluno a partir dos conceitos e dos conteúdos da ciência química.

\section{Resultados e Discussão}

Considerando o perfil do grupo de professores de química que participou desta pesquisa $(n=92)$, em relação as categorias Gênero, Faixa Etária e Maior Grau de Formação, tem-se que 57,6\% ( $n=53)$ se caracterizam como sendo do gênero feminino, 40,2\% $(n=37)$ expõem que se enquadram no gênero masculino, e 2,2\% $(n=2)$ optaram pela opção outro. Destes sujeitos, 4,3\% ( $\mathrm{n}=4)$ possuem idade inferior ou igual a 25 anos, 10,9\% $(\mathrm{n}=10)$ afirmam possuir idade entre 25 e 30 anos, 20,7\% $(n=20)$ ajuízam ter idade entre 30 e 35 anos, 15,2\% $(\mathrm{n}=14)$ possuem idade entre 35 e 40 anos, $17,4 \%(\mathrm{n}=16)$ afirmam possuir idade entre 40 e 45 anos, e 31,5\% $(n=29)$ afirmam ter idade igual ou superior a 45 anos. Em relação ao maior grau de formação destes sujeitos, $19,6 \%(\mathrm{n}=18)$ tem graduação, $14,1 \%(\mathrm{n}=13)$ possui especialização, 16,3\% $(\mathrm{n}=15)$ têm mestrado, 38\% $(\mathrm{n}=35)$ têm doutorado, e $12 \%(\mathrm{n}=11)$ têm de pós-doutorado.

Em detrimento do perfil dos sujeitos, bem como das assertivas presentes na Tabela 1, por meio do Programa SPSS, fez-se a análise Estatística Descritiva, considerando a média, o desvio padrão e os mínimo e máximo para cada assertiva, como se expõe no Quadro 1.

Quadro 1: Análise Estatística Descritiva

\begin{tabular}{|ccccc|}
\hline Código & Mínimo & Máximo & Média & Desvio Padrão \\
\hline A & 2 & 5 & 4,32 & 0,811 \\
\hline B & 3 & 5 & 4,42 & 0,745 \\
\hline C & 2 & 5 & 4,60 & 0,757 \\
\hline D & 2 & 5 & 4,33 & 0,800 \\
\hline E & 2 & 5 & 4,70 & 0,624 \\
\hline F & 2 & 5 & 4,62 & 0,709 \\
\hline G & 1 & 5 & 3,70 & 1,126 \\
\hline
\end{tabular}

Fonte: dados da pesquisa, 2020. 
Em relação a análise estatística das assertivas, pode-se perceber no Quadro 1 que, com exceção da assertiva $\mathrm{G}$, a qual apresenta grau mínimo de 1 e máximo de 5 e da assertiva B, que tem grau mínimo de 3 e máximo de 5, as demais assertivas possuem apontamento no grau mínimo de 2 e no grau máximo de 5, o que pressupõe uma dispersão significativa de apontamento em todos os escores, variando do grau extremo de concordância ao grau terminal de discordância. Em relação as médias, percebe-se que existe uma variação não significativa entre as assertivas variantes de A a F, com exceção da assertiva $G$, a qual apresenta uma média relativamente baixa em relação as demais. Neste sentido, apesar de estatisticamente não haver uma significância em relação as médias, é possível averiguar que há uma sequência lógica de concordância em relação as assertivas, considerando primordialmente a assertiva E, seguida das assertivas F, C, B, D, A e G, respectivamente.

Ainda em menção a análise estatística, evidencia-se no Quadro 1 uma diferença exponencial em relação aos desvios-padrões das diferentes assertivas, considerando o menor para a assertiva $E(D P=0,624)$ e o maior para a assertiva $G(D P=1,126)$. Isto é, em detrimento e inversamente as médias, há uma dispersão significativa em relação aos apontamentos dos professores no que diz respeito aos escores da assertiva $\mathrm{G}$, considerando os 5 graus possíveis na escala Likert. Afinal, entende-se que quanto maior o desvio padrão de uma amostra maior é a dispersão de apontamento nos graus de concordância entre os sujeitos. Neste sentido, para ilustrar detalhadamente e sistematicamente os apontamentos dos professores em relação as assertivas, plotou-se o Quadro 2. Neste quadro é possível perceber o número de apontamentos que cada assertiva recebeu em determinados escores, bem como o percentual característico de cada um.

Quadro 2: Percentual e número de apontamento por escore em cada assertiva.

\begin{tabular}{|ccccccc|}
\multicolumn{5}{c}{} & \multicolumn{5}{c|}{ Escores } \\
\hline Código & $\mathbf{1}$ & $\mathbf{2}$ & $\mathbf{3}$ & $\mathbf{4}$ & $\mathbf{5}$ \\
\hline $\mathbf{A}$ & $0 \%(\mathrm{n}=0)$ & $3,3 \%(\mathrm{n}=3)$ & $12 \%(\mathrm{n}=11)$ & $34,8 \%(\mathrm{n}=32)$ & $50 \%(\mathrm{n}=46)$ \\
B & $0 \%(\mathrm{n}=0)$ & $0 \%(\mathrm{n}=0)$ & $15,2 \%(\mathrm{n}=14)$ & $27,2 \%(\mathrm{n}=25)$ & $57,6 \%(\mathrm{n}=53)$ \\
C & $0 \%(\mathrm{n}=0)$ & $3,3 \%(\mathrm{n}=3)$ & $6,5 \%(\mathrm{n}=6)$ & $17,4 \%(\mathrm{n}=16)$ & $72,8 \%(\mathrm{n}=67)$ \\
D & $0 \%(\mathrm{n}=0)$ & $3,3 \%(\mathrm{n}=3)$ & $10,9 \%(\mathrm{n}=10)$ & $35,9 \%(\mathrm{n}=33)$ & $50 \%(\mathrm{n}=46)$ \\
E & $0 \%(\mathrm{n}=0)$ & $1,1 \%(\mathrm{n}=1)$ & $5,4 \%(\mathrm{n}=5)$ & $16,3 \%(\mathrm{n}=15)$ & $77,2 \%(\mathrm{n}=71)$ \\
F & $0 \%(\mathrm{n}=0)$ & $1,1 \%(\mathrm{n}=1)$ & $9,8 \%(\mathrm{n}=9)$ & $15,2 \%(\mathrm{n}=14)$ & $73,9 \%(\mathrm{n}=68)$ \\
G & $3,3 \%(\mathrm{n}=3)$ & $13 \%(\mathrm{n}=12)$ & $23,9 \%(\mathrm{n}=22)$ & $30,4 \%(\mathrm{n}=28)$ & $29,3 \%(\mathrm{n}=27)$ \\
\hline
\end{tabular}

Fonte: dados da pesquisa, 2020. Legenda: $\mathrm{n}=$ número de sujeitos. 
Interpretando-se o Quadro 2, percebe-se que há uma dispersão muito significativa em relação aos apontamentos dos professores para a assertiva $\mathrm{G}$, o que não ocorre com as demais assertivas, em especial com a assertiva $\mathrm{E}$, onde a maioria dos apontamentos se concentra nos escores 4 e 5; logo, o desvio padrão da assertiva $\mathrm{G}$ é maior que os demais. Neste sentido, ainda é possível averiguar a classificação da média das assertivas em detrimento do percentual de professores que pontuam os escores 4 e 5, os dois maiores escores da escala Likert. Todavia, o que chama a atenção são as assertivas A e B, pois ambas apresentaram o mesmo número de professores que pontuam os escores representativos do grau de concordância, mas possuem médias diferentes. Neste sentido, pode-se afirmar que a média da assertiva $B(M=4,42, n=78)$ é maior do que a média da assertiva $A(M=4,32, n=78)$ porque há um número maior de professores que aponta o grau 5 para a assertiva $\mathrm{B}(\mathrm{n}=53)$, em referência a assertiva A $(n=46)$. Assim, entende-se que apesar de o número de professores que assinala o grau de concordância para ambas as assertivas ser o mesmo, esse número difere quando observado detalhadamente o apontamento nos escores individuais.

Em decorrência da pequena diferença supradestacada, buscou-se averiguar detalhadamente as assertivas, bem como entender se há significância de seus apontamentos com referência aos professores. Para tal processo, realizou-se a estatística de teste do teste não paramétrico de Kruskal-Wallis (Quadro 3) à luz das categorias Gênero, Faixa Etária e Maior Grau de Formação; os pressupostos banalizadores desta ação foram os dados expostos na Tabela 1. Neste processo, assegura-se ser possível identificar, somente por meio do teste de Kruskal-Wallis com três ou mais amostras diferentes, se há ou não retenção da hipótese nula, a qual se fundamenta na ideia de que os apontamentos dos sujeitos, indiferente da categoria estipulada, são os mesmos para as diferentes assertivas. Todavia, caso seja necessário rejeitar a hipótese nula, prioriza-se a ideia de que há divergência de apontamentos entre os sujeitos, destacando-se a categoria e a assertiva, o que possibilita a emersão da hipótese alternativa. Assim, afirma-se que a existência da hipótese alternativa emerge quando, para uma determinada assertiva, a significância for um valor menor que 0,05 .

Ao tocante, no Quadro 3, apresenta-se os resultados que derivam da análise da estatística de teste referente as categorias Gênero, Faixa Etária e Maior Grau de Formação. 
Quadro 3: Estatística de teste via Kruskal-Wallis para as categorias.

\begin{tabular}{|c|c|c|c|c|c|c|c|}
\hline \multicolumn{8}{|c|}{ Variável de Agrupamento: Gênero } \\
\hline & $\mathbf{A}$ & B & $\mathbf{C}$ & D & $\mathbf{E}$ & $\mathbf{F}$ & G \\
\hline Qui-quadrado & 1,396 & 2,137 & 8,454 & 3,910 & 11,999 & 0,900 & 2,733 \\
\hline $\mathrm{gl}$ & 3 & 3 & 3 & 3 & 3 & 3 & 3 \\
\hline Significância Assint. & 0,707 & 0,544 & 0,038 & 0,271 & 0,007 & 0,825 & 0,435 \\
\hline \multicolumn{8}{|c|}{ Variável de Agrupamento: Faixa Etária } \\
\hline & $\mathbf{A}$ & B & $\mathbf{C}$ & D & $\mathbf{E}$ & $\mathbf{F}$ & G \\
\hline Qui-quadrado & 4,240 & 3,622 & 6,157 & 7,540 & 10,003 & 4,573 & 1,741 \\
\hline $\mathrm{gl}$ & 5 & 5 & 5 & 5 & 5 & 5 & 5 \\
\hline Significância Assint. & 0,515 & 0,605 & 0,291 & 0,183 & 0,075 & 0,470 & 0,884 \\
\hline \multicolumn{8}{|c|}{ Variável de Agrupamento: Maior Grau de Formação } \\
\hline & $\mathbf{A}$ & B & $\mathbf{C}$ & $\mathbf{D}$ & $\mathbf{E}$ & $\mathbf{F}$ & $\mathbf{G}$ \\
\hline Qui-quadrado & 8,729 & 2,616 & 1,139 & 3,860 & 2,647 & 3,569 & 8,360 \\
\hline $\mathrm{gl}$ & 4 & 4 & 4 & 4 & 4 & 4 & 4 \\
\hline Significância Assint. & 0,068 & 0,624 & 0,888 & 0,425 & 0,619 & 0,467 & 0,079 \\
\hline
\end{tabular}

Fonte: dados da pesquisa, 2020.

Em decorrência do exposto no Quadro 3, considerando o valor da significância para todas as assertivas, indiferente da categoria, percebe-se, com exceção das assertivas $\mathrm{C}$ e $\mathrm{E}$ na categoria de agrupamento Gênero, uma significância maior que 0,05 ( $p>0,05)$. Assim, podese assegurar por meio da retenção da hipótese nula de que estatisticamente não há diferença de apontamento entre sujeitos para as diferentes assertivas em referência as categorias Faixa Etária e Maior Grau de Formação, bem como para as assertivas A, B, D, F e G referentes a categoria Gênero. Todavia, como destacado, deve-se rejeitar a hipótese nula para as assertivas $\mathrm{C}$ e $\mathrm{E}$ referentes a categoria Gênero. Isto é, para estas assertivas, estatisticamente há diferença de apontamento entre os sujeitos dos diferentes Gêneros, visto que estes influenciam no grau de concordância sobre a ideia de ensinar química porque auxilia o aluno a tornar-se um cidadão ético e consciente cientificamente, caracterizado pela assertiva $\mathrm{C}$ $\left[\mathrm{X}^{2}(3)=8,454 ; \mathrm{p}<0,05\right]$, e pela razão de ensinar química porque se proporcionar ao aluno o desenvolvimento de uma visão crítico-científica sobre o mundo, descrita pela assertiva E C $\left[\mathrm{X}^{2}(3)=11,999 ; \mathrm{p}<0,05\right]$.

Nesta ótica, em decorrência da estatística apresentada a partir dos dados quantificados, expõe-se a seguir uma discussão interpretativa de viés qualitativo, a qual emerge a partir dos dados estabelecidos à luz de teóricos da área. Tal discussão é importante por buscar entender quais são as razões que motivam os professores de química a ensinar esta ciência na Educação Básica. Para tanto, por meio da Estatística Descritiva (Quadro 1), elenca-se um perfil de 
discussão, sem enfatizar a categorização, iniciando-se pela assertiva $\mathrm{E}$ e finalizando-se com a assertiva $\mathrm{G}$, a fim de organizar uma estrutura que aponta as implicações mais pertinentes deste movimento, a partir da concepção deste grupo de professores, na Educação Básica.

Neste linear, tem-se que 93,5\% ( $\mathrm{n}=86)$ dos professores ensinam química na Educação Básica porque esta ciência proporciona ao aluno o desenvolvimento de uma visão críticocientífica sobre o mundo. Deste modo, entende-se que a grande maioria dos professores apresenta uma concepção de que ensinar química na Educação Básica não é um processo meramente de inserção de conceitos e de conteúdos, mas um espaço para possibilitar ao aluno aprender criticamente, entendendo de forma autônoma e científica o próprio contexto. Tal pressuposto atribui significados relevantes ao compreender que a criticidade não está associada ao conteúdo, mas na constituição da identidade da pessoa, considerando os conteúdos atitudinais e procedimentais essenciais para a atribuição de sentidos idiossincrático aos objetos de conhecimento da ciência química relativos a formação científica do aluno.

Não diferente, $89,1 \%(\mathrm{n}=82)$ dos professores ensinam química porque é uma ciência que propicia a Alfabetização Científica, a argumentação crítica e o pensamento científico. Neste sentido, em decorrência do exposto anteriormente, percebe-se que o ensino de química na Educação Básica está mais voltado no sentido da constituição de uma identidade crítica e reflexiva do que no sentido de uma aprendizagem mecânica e conteudista, possibilitando que os objetos de conhecimento desta ciência sejam desenvolvidos de forma não linear e não arbitrária. Neste sentido, Bedin e Del Pino (2019, p. 1373) expõem que um ensino desta magnitude desperta nos sujeitos, além da compreensão do próprio papel no processo de aprender, "a autenticidade na formação, demonstrando que o importante na Educação Básica não é fazer, mas aprender a partir do aprender a fazer". Os autores ainda complementam que "a aprendizagem do aluno de forma crítica, autônoma e reflexiva" é capaz de despertar "neste a curiosidade, a argumentação crítica e o interesse pela ciência" (BEDIN; DEL PINO, 2018, p. 351).

Além disso, 90,2\% (n=83) dos professores ajuízam ensinar química na Educação Básica porque é uma forma de auxiliar o aluno a tornar-se um cidadão ético e consciente cientificamente. Este processo demonstra a seriedade destes professores em relação a formação da identidade do aluno, assegurando a constituição do sujeito a partir de habilidades básicas para a cidadania, como a capacidade de participar ativamente de um processo e a seriedade de tomar decisões (SANTOS; SCHNETZLER, 2003). Para tanto, segundo Bedin (2020, p. 238), "é necessário enfatizar a aprendizagem em si, pois no processo de ensinagem dos conceitos, as ideias e os métodos devem ser abordados mediante a exploração de problemas, a interpretações e a resoluções". Este desenho é relevante na medida em que o autor complementa que os processos de ensino e de aprendizagem se findam em uma "integração dialética entre o instrutivo e o educativo, contribuindo para a formação integral da personalidade do aluno" (BEDIN, 2015, p. 42).

Em detrimento do supracitado, 84,8\% $(\mathrm{n}=78)$ dos professores ensinam química aos alunos para possibilitar-lhes a ação de ler o mundo por meio dos óculos desta ciência. Isto é, a partir da concepção de que entender o mundo por meio da ciência química é uma forma de 
compreender o conhecimento científico dentro do conhecimento sociocultural do aluno, usufruindo deste para melhorar a própria realidade, percebe-se que estes professores buscam "contribuir para uma visão mais ampla do conhecimento científico, de forma a melhorar a compreensão do mundo e contribuir para a formação da cidadania dos alunos" (LIMA; MERÇOM, 2011, p. 202). Neste sentido, Santos e seus colaboradores (2013, p. 1) afirmam que a importância de estudar química encontra-se na ação de "possibilitar o desenvolvimento de uma visão crítica de mundo, podendo analisar, compreender, e principalmente utilizar o conhecimento construído em sala de aula para a resolução de problemas sociais, atuais e relevantes para sociedade".

Nesta perspectiva, 85,9\% $(\mathrm{n}=79)$ dos professores afirmam que ensinar química na Educação Básica é uma forma de apresentar e de desenvolver os conceitos e os conteúdos da ciência. Este processo é importante na medida em que se compreende que um dos objetivos da ciência química é "possibilitar aos alunos a compreensão das transformações químicas que ocorrem no mundo físico de forma abrangente e integrada, para que estes possam julgála com fundamentos teórico-práticos" (ROCHA; VASCONCELOS, 2016, p. 1). Portanto, trabalha-se química na Educação Básica também em um viés de conteúdos científicos para que o sujeito consiga, de acordo com Bedin e Del Pino (2020, p. 365), "mobilizar suas competências para entender o conteúdo científico relacionado ao seu interesse". Esta ação exige do sujeito, na concepção dos autores, "além de uma organização de ideias e otimização de espaço/tempo, segurança significativa em relação a criticidade e a autonomia", pois "temse a formação de uma argumentação e de uma consciência crítica para expressar conhecimento específico na (re)construção de saberes e na produção de novos conhecimentos" (BEDIN; DEL PINO, 2020, p. 365).

Neste desenho, Millar (2003) corrobora afirmando que o conhecimento científico, considerado como algo cultural e de poder intelectual, apresenta a capacidade de deduzir a curiosidade e aumentar o arbítrio sobre as concepções das pessoas em relação ao mundo e a vida. Portanto, o conhecimento científico é essencial para instigar nos sujeitos algumas ações, como tomar decisões práticas relacionadas ao próprio contexto e se posicionar em movimentos e em assuntos que envolvam os componentes da ciência e da tecnologia. Assim, entende-se que o conteúdo científico é importante para a constituição da identidade críticocientífica do sujeito, mas deve-se haver uma reflexão em relação as suas aplicações e as suas implicações na sociedade, no meio, no mundo. Esta ação é necessária para que o conteúdo científico seja desenvolvido com viés de formação procedimental e atitudinal, e não simplesmente para que o aluno possa vislumbrar a ciência química em códigos, símbolos e números.

Ainda, 84,8\% $(n=78)$ dos sujeitos ensinam química para potencializar a formação científica do aluno, pois julgam ser importante "possibilitar o desenvolvimento de uma visão crítica de mundo, podendo analisar, compreender, e principalmente utilizar o conhecimento construído em sala de aula para a resolução de problemas sociais, atuais e relevantes para sociedade" (ROCHA; VASCONCELOS, 2016, p. 5). É neste sentido que, de acordo com Bedin (2020, p. 237), as ações pedagógicas no ensino de química precisam instigar a "concepção da identidade científica no sujeito na medida em que lhe possibilita desenvolver 
e interpretar saberes à luz de conceitos básicos e específicos, estimulando a mobilização de competências em um sujeito que questiona, reflete e raciocina sobre o seu contexto".

Todavia, 59,7\% $(\mathrm{n}=55)$ dos professores desenvolvem um ensino de química na Educação Básica pensando em proporcionar ao sujeito ações para mobilizar as competências e desenvolver as habilidades elencadas na Base Nacional Comum Curricular (BNCC). Neste sentido, é possível perceber que um percentual relativamente intermediário do grupo de professores se importa com as competências e as habilidades presentes no documento. Assim, hipoteticamente, acredita-se que 40,3\% ( $\mathrm{n}=37)$ dos professores ainda não conhecem ou entendem o documento que rege, aproximadamente, $60 \%$ da padronização do currículo, ou não se importam com o mesmo, pois segundo o documento, as competências e as habilidades "exploram situações-problema envolvendo melhoria da qualidade de vida, segurança, sustentabilidade, diversidade étnica e cultural, entre outras" (BRASIL, 2017, p. 550).

Em síntese, pode-se compreender que os professores ensinam química na Educação Básica porque julgam importante a formação de um sujeito crítico, autônomo e intelectualmente capacitado para, em meio a competências e a habilidades relacionadas aos objetos de conhecimento da ciência química, tomar decisões e atuar ativamente na sociedade. Além disso, percebe-se a concepção de que é preciso ensinar química de forma universal e tangível a realidade do aluno, buscando-se subsídios em seu contexto, para que este possa se constituir como pessoa potencialmente significativa, capaz de argumentar criticamente, pensar cientificamente e entender o mundo a partir de uma identidade crítico-científica.

\section{Conclusão}

Considerando o exposto neste texto, e visando o objetivo central do mesmo, a fim de averiguar as concepções de um grupo de professores em relação ao "Por que ensinar química?", é perceptível que o grupo de professores participantes desta pesquisa almeja a formação de um sujeito para além dos saberes curriculares, fundamentado nas concepções éticas e morais da ciência química com vistas a formação para a cidadania. Para tanto, é necessário afirmar que tal processo exige do professor um ensino contextualizado e uma ação potencializadora, capaz de despertar no aluno o interesse pela ciência e o senso crítico, fundamentado na argumentação e na reflexão científica. Este processo é importante para fazer com que o sujeito entenda o seu papel no processo de aprender, desenvolvendo ações que ultrapassam o simples desejo de memorizar.

Em detrimento da análise estatística, pode-se perceber que a maioria deste grupo de professores se caracteriza como sendo do gênero feminino, possuindo uma idade igual ou superior a 45 anos e com doutorado. Ainda, pode-se inferir que o ensino de química na Educação Básica é desenvolvido por uma sequência lógica de razões, porque: i) se possibilita uma compreensão crítico-científica do mundo; ii) se propicia a argumentação crítica e o pensamento científico à luz da Alfabetização Científica; iii) se auxilia na formação ética e intelectualmente científica do aluno; iv) se proporciona o entendimento dos objetos de conhecimento da ciência química no mundo social; v) se evidencia os conceitos e os 
conteúdos científicos da ciência; vi) se potencializa a formação científica do aluno; e, vii) se permite a mobilização de competências e o desenvolvimento de habilidades elencadas na BNCC.

Nesta vertente, pode-se aferir que o ensino de química encaminha-se para um processo significativo de aprendizagem, no qual o professor assume uma identidade pautada na concepção de que a química, historicamente construída por pessoas para atender as diferentes necessidades sociais, deve ser construída e ensinada/desenvolvida na Educação Básica em referência a formação crítico-científica de pessoas, as quais aprendem e usufruem dos objetos de conhecimento da ciência química a partir da interação e da colaboração, com vistas a reflexões e diálogos que ultrapassam o senso científico. Ademais, esta pesquisa desdobra-se no sentido de investigar novas questões, tais como: Como ensinar química? e $O$ que ensinar de química?, a fim de que a tríade $O$ que ensinar?, Como ensinar?, e Por que ensinar? seja entendida a partir das concepções do seu maior grau de referência: o professore que ensina química.

Notas:

1. O teste de Kruskal-Wallis é um teste não paramétrico utilizado na comparação de três ou mais amostras independentes. A aplicação do teste serve para indicar se há diferença em pelo menos dois grupos de análise, a qual deriva da transformação dos valores numéricos em postos, agrupados em apenas um conjunto de dados.

\section{Referências}

AIKENHEAD, Glen S. Educação científica para todos. Mangualde: Edições Pedago, 2009.

BEDIN, Everton. A emersão da interdisciplinaridade no Ensino Médio Politécnico: relações que se estabelecem de forma colaborativa na qualificação dos processos de ensino e aprendizagem à luz das Tecnologias de Informação e Comunicação. (Doutorado em Educação em Ciências: química da vida e saúde) - Instituto de Ciências Básicas da Saúde, Universidade Federal do Rio Grande do Sul, Porto Alegre/RS, 2015. Disponível em: http://hdl.handle.net/10183/126836. Acesso em: 10 set. 2020.

Filme, Experiência e Tecnologia no Ensino de Ciências Química: uma sequência didática. Revista de

Educação, Ciências e Matemática, v. 9, n. 1, 2019. Disponível em: http://publicacoes.unigranrio.edu.br/index.php/recm/article/view/4280. Acesso em: 10 set. 2020.

Do algodão doce à bomba atômica: avaliações e aspirações do aprender pela pesquisa no ensino de Química. Debates em Educação, v. 12, n. 27, p. 236-253, 2020. Disponível em: https://doi.org/10.28998/2175-6600.2020v12n27p236-253. Acesso em: 10 set. 2020.

BEDIN, Everton; DEL PINO, José Claudio. Dicumba - el aprender por la investigación en el aula: los saberes científicos de química en el contexto sociocultural del alumno. Góndola, enseñanza y aprendizaje de las $\begin{array}{lllllll}\text { ciencias, } & \text { v. } & 13, & \text { n. } & 2018 . & \text { Disponível } & \text { em: }\end{array}$ https://revistas.udistrital.edu.co/ojs/index.php/GDLA/article/view/13055/pdf. Acesso em: 20 ago. 2020.

Das Incertezas às Certezas da Pesquisa não Arbitrária em Sala De Aula Via Metodologia Dicumba. Currículo sem Fronteiras, v. 19, n. 3, p. 1358-1378, 2019. Disponível em: 
http://curriculosemfronteiras.org/vol19iss3articles/bedin-delpino.pdf. Acesso em: 13 set. 2020.

La movilización de competencias y el desarrollo cognitivo universal-bilateral del aprendizaje en la enseñanza de las ciencias. Paradigma, 2020. Disponível em: DOI: https://doi.org/10.37618/PARADIGMA.1011-2251.2020.p360-383.id804. Acesso em: 10 set. 2020.

BRASIL. Base Nacional Comum Curricular. Brasília: MEC, 2017. Disponível em: http://basenacionalcomum.mec.gov.br/images/BNCC_20dez_site.pdf. Acesso em: 22 ago. 2020.

CRESWELL, John W. Projeto de pesquisa métodos qualitativo, quantitativo e misto. Porto Alegre: Artmed, 2007.

DAL-FARRA, Rossano André; LOPES, Paulo Tadeu Campos. Métodos mistos de pesquisa em educação: pressupostos teóricos. Nuances: estudos sobre Educação, v. 24, n. 3, p. 67-80, 2013. Disponível em: http://dx.doi.org/10.14572/nuances.v24i3.2698. Acesso em: 5 set. 2020.

DE MORAES, Caroline da Silva; BEDIN, Everton. Indisciplina e falta de autonomia em sala de aula: fatores que influenciam nos processos de ensino-aprendizagem. Pedagogia em Foco, v. 12, n. 8, p. 114-133, 2017. Disponível em: https://doi.org/10.29031/pedf.v12i8.314. Acesso em: 10 set. 2020.

FINGER, Isadora; BEDIN, Everton. A contextualização e seus impactos nos processos de ensino e aprendizagem da ciência química. Revista Brasileira de Ensino de Ciências e Matemática, v. 2, n. 1, p. 8-24, 2019. Disponível em: https://doi.org/10.5335/rbecm.v2i1.9732. Acesso em: 10 set. 2020.

LIMA, Verônica Ferreira; MERÇON, Fábio. Metais pesados no ensino de química. Química nova na escola, v. 33, n. 4, p. 199-205, 2011. Disponível em: https://www.ufjf.br/baccan/files/2012/11/199-CCD-7510.pdf. Acesso em: 16 set. 2020.

MARTINS, Carmen Maria Caro et al. Por um novo currículo de ciências para as necessidades de NOSSO TEMPO. Presença Pedagógica, v. 9, n. 51, 2003.

MILLAR, Robin. Um currículo de ciências voltado para a compreensão por todos. Ensaio Pesquisa em Educação em Ciências, v. 5, n. 2, p. 73-91, 2003. Disponível em: https://www.redalyc.org/pdf/1295/129517970006.pdf. Acesso em: 10 set. 2020.

ROCHA, Joselayne Silva; VASCONCELOS, Tatiana Cristina. Dificuldades de aprendizagem no ensino de química: algumas reflexões. Encontro Nacional de Ensino de Química, v. 18, p. 1-8, 2016. Disponível em: http://www.eneq2016.ufsc.br/anais/resumos/R0145-2.pdf. Acesso em: 16 set. 2020.

SANTOS, Wildson Luiz Pereira dos; SCHNETZLER, Roseli Pacheco. Educação em química: compromisso com a cidadania. 3. ed. Porto Alegre: UNIJUI, 2003.

SANTOS, Anderson Oliveira et al. Dificuldades e motivações de aprendizagem em Química de alunos do ensino médio investigadas em ações do (PIBID/UFS/Química). Scientia plena, v. 9, n. 7 (b), 2013. Disponível em: https://www.scientiaplena.org.br/sp/article/viewFile\%20/1517/812. Acesso em: 2 set. 2020.

SAVIANI, Dermeval. Formação de professores no Brasil: dilemas e perspectivas. Poíesis Pedagógica, v. 9, n. 1, p. 07-19, 2011. Disponível em: https://doi.org/10.5216/rpp.v9i1.15667. Acesso em: 16 set. 2020.

TASHAKKORI, Abbas; CRESWELL, John W. The new era of mixed methods. Journal of Mixed Methods Research, v. $1, \quad$ n. $1, \quad$ p. $\quad 3-7, \quad 2007 . \quad$ Disponível em: https://journals.sagepub.com/doi/pdf/10.1177/2345678906293042. Acesso em: 10 set. 2020.

\section{Correspondência}

Everton Bedin: Doutor e pós-doutor em Educação em Ciências pela Universidade Federal do Rio Grande do Sul (UFRGS); Mestre em Educação Química pela Universidade Federal de Uberlândia (UFU); Especialista em Gestão Educacional pela Universidade Federal de Santa Maria (UFSM) e em Tecnologias da Informação e Comunicação pela Universidade Federal do Rio Grande (FURG); 
Licenciatura em Química pela Universidade de Passo Fundo (UPF). Professor Permanente no Departamento de Química e nos Programas de Pós-Graduação em Educação em Ciências e em Matemática (PPGECM) e Mestrado Profissional em Química em Rede Nacional (PROFQUI) da Universidade Federal do Paraná (UFPR).

E-mail: bedin.everton@gmail.com

Orcid: https://orcid.org/0000-0002-5636-0908

Texto publicado em Currículo sem Fronteiras com autorização dos autores. 